\title{
Article
}

\section{Can the WiMAX IEEE 802.16 Standard Be Used to Resolve Last-Mile Connectivity Issues in Botswana?}

\author{
Malebogo Mokeresete ${ }^{1,2, *}$ and Bukohwo Michael Esiefarienrhe ${ }^{1, *(D)}$ \\ 1 Computer Science and Information Systems Department, North-West University, \\ Mahikeng 2745, South Africa \\ 2 Computer Science and Information Technology Department, Sol Plaatje University, \\ Kimberly 8300, South Africa \\ * Correspondence: m.mokeresete@spu.ac.za (M.M.); 25840525@nwu.ac.za (B.M.E.)
}

Citation: Mokeresete, M.; Esiefarienrhe, B.M. Can the WiMAX IEEE 802.16 Standard Be Used to Resolve Last-Mile Connectivity Issues in Botswana? Telecom 2022, 3, 150-162. https://doi.org/10.3390/ telecom 3010010

Academic Editor: AlexandrosApostolos A. Boulogeorgos

Received: 8 September 2021 Accepted: 28 January 2022 Published: 8 February 2022

Publisher's Note: MDPI stays neutral with regard to jurisdictional claims in published maps and institutional affiliations.

Copyright: (C) 2022 by the authors. Licensee MDPI, Basel, Switzerland. This article is an open access article distributed under the terms and conditions of the Creative Commons Attribution (CC BY) license (https:/ / creativecommons.org/licenses/by/ $4.0 /)$.

\begin{abstract}
Some of the advantages of using Worldwide Interoperability Microwave Access (WiMAX) technology at the last-mile level as an access technology include an extensive range of $50 \mathrm{~km}$ Line of Sight (LOS), 5 to $15 \mathrm{~km}$ Non-Line of Sight, and fewer infrastructure installations compared to other wireless broadband access technologies. Despite positive investments in ICT fiber infrastructure by developing countries, including Botswana, servicing end-users is subjected to high prices and service disparities. The alternative, the Wi-Fi hotspot initiative by the Botswana government, falls short as a solution for last-mile connectivity and access. This study used OPNET simulation Modeler 14.5 to investigate whether Botswana's national broadband project could adopt WiMAX IEEE 802.16e as an access technology. Therefore, using the experimental method, the simulation evaluated the WiMAX IEEE $802.16 \mathrm{e} / \mathrm{m}$ over three subscriber locations in Botswana. The results obtained indicate that the deployment of the WiMAX IEEE 802.16e standard can solve most of the deployment issues and access at the last-mile level. Although the findings suggest that WiMAX IEEE 802.16e is more suitable for high-density areas, it could also solve rural areas' infrastructure development challenges and provide the required high-speed connectivity access. However, unlike the Wi-Fi initiative, which requires more infrastructure deployment and relies less on institutional and regulatory frameworks, the deployment of WiMAX IEEE 802.16e necessitates institutional and regulatory standards.
\end{abstract}

Keywords: WiMAX IEEE 802.16e; national broadband project; rural area connectivity; connectivity challenges in developing countries

\section{Introduction}

Generally, the public [1,2] has expressed concerns that the National Broadband Project, intended to provide affordable and universal services, has not delivered results and has failed. This situation led the public, including former senior government official for the Minister of Works, Transport, and Communications, David Magang, to express dissatisfaction about the project's failure to meet the targets and deliverables of the national broadband project rollout [3]. Magang warned that lack of connectivity and access could generate a distant dream rather than realistic aspirations due to a lack of affordability, quality service, and access. The former minister decried the persistent lack of affordable internet access to practical high-speed internet, and further warned the government to expedite the review of the national broadband project and ensure that the government realized the intended goals for innovation and creativity as the bedrock of the economy [3]. Many villages in Botswana, including with proximity to cities, towns, and urban areas, lack connectivity and access. For example, Kopong, Matseta, Gakuto, Ga-Modubu, and Manoko are cluster villages and experience broadband connectivity and access disparity, yet they are close by, and are not more than $10 \mathrm{~km}$ from each other. In addition, many villages are within 10 to $30 \mathrm{~km}$ apart and experience a disturbing lack of high-speed networks, for example, Samochima, 
Shakawe, Sepopa, and others with similar characteristics. This pattern suggests that service providers experience colossal costs due to sparse settlement patterns. The situation places an enormous challenge on the government and on service providers to provide infrastructure deployment and last-mile level connectivity and access [4]. WiMAX IEEE 802.16e, a relatively new access technology that allows for interface with LTE technologies, presents an opportunity [5] for Botswana's aspiration for a knowledge-based economy and for meeting connectivity for all. Developing countries, including Botswana, experience high infrastructure network development costs, exacerbated by highly scattered settlement patterns, low population density, and low income challenges [6]. These challenges negatively affect broadband services' expansion and speak to the alarming digital divide.

Despite substantive investments in national fiber infrastructure development institutional and regulatory frameworks, many people cannot afford broadband services in Botswana. For example, in a study of 230 countries, Botswana ranked 167 among the most expensive for internet access and experienced urban skewed broadband services at the last mile level [7]. However, besides infrastructure challenges, the government needs to choose an appropriate technology for deployment that addresses low population densities, sparse settlement patterns, and low rural income. Many countries have introduced metro-Wi-Fi services (hotspot) to reduce access costs and improve efficiency. The intervention threatens MNOs and presents regulatory issues by turning wholesale and spectrum managers into service providers and competitors. In addition, instead of focusing on the spectrum and wholesale services management, the government has turned into a hotspot service provider. Such conflicting roles suggest a gap that requires developing frameworks to provide primary and subsidized broadband services.

However, given the glaring connectivity and access challenges, Botswana's fiber infrastructure network goals and plans for connectivity for all remain far-fetched. The available literature indicates that broadband deployment has relied on wireless broadband technologies more than fixed, especially LTE and WiMAX IEEE 802.16e [8]. The following discussion presents WiMAX IEEE 802.16e testbed simulations and determines whether the government could benefit from the technology as an access medium for last-mile connectivity and access.

\section{Background}

Studies indicate that developing countries' settlement patterns present infrastructure development challenges for the deployment of services [8]. Settlements have close and scattered proximity and lower population densities and incomes, affecting resource mobilisation and the fair distribution of infrastructure development and business viability. Furthermore, low population densities, low rural income, and lack of local application content affect the expansion and adoption of broadband services, including internet use. Challenges include the lack of institutional capacity, the void created by high prices charged by MNOs, and the lack of primary network access to provide an alternative connectivity network. Governments across developed and developing countries have introduced wireless fidelity (Wi-Fi hotspot) networks to address the lack of affordable services and internet access, and for improved public service efficiency.

Despite the successful government deployment of a substantive fibre infrastructure development and other frameworks, many users complain about high broadband services, poor network services, and a lack of e-government services. Communities in developing countries often settle in sparse-location patterns approximately less than 10 to $40 \mathrm{~km}$ apart, which demand MNOs, ISPs, and other service providers to install more infrastructure development, and require added resources [9]. For example, although Tlhareseleele, Rakhuna, and other villages are less than 10 to $40 \mathrm{~km}$ from Pitsane/Goodhope, which have an adequate ICT infrastructure, they experience limited network services. Most of the time, these cluster villages access roaming broadband services across from South Africa's MNOs [10].

Therefore, this study noted that many deployments in developing countries, including Botswana, predominately rely on LTE, notwithstanding the many successful deployments 
of the WiMAX IEEE 802.16 Standard reluctant to adopt the technology. Many studies have point out that WiMAX IEEE 802.16 addresses developing countries' lack of infrastructure development and significantly reduces the cost of infrastructure deployments. Therefore, this study adopted experimental and simulated WiMAX IEEE 802.16 for access at the last-mile level.

Notwithstanding the gains from the Wi-Fi hotspot initiative, public Wi-Fi services have eased congestion and enhanced service delivery, particularly in the banking sector. As a result, many people access statements, transfer funds, and use other online services outside banking halls. In addition, the introduced metro-based Wi-Fi hotspot initiatives provide service end-users with alternative access away from the high tariffs charged by MNOs and ISPs. However, despite the Wi-Fi hotspot advantages, the initiative has limited coverage, requires extensive network infrastructure deployment, and may not work for rural areas. The expansion of Wi-Fi hotspots requires a series of added infrastructure and network installations, including institutional and regulatory frameworks, to address management, maintenance, and regulatory issues.

Nevertheless, developing countries could adopt more advanced wireless technologies to address the prevalent lack of infrastructure development, high infrastructure deployment costs, and lack of business viability in rural areas. Among the wireless technologies available, Worldwide Interoperability for Microwave Access (WiMAX IEEE 802.11) stands out as a possible solution for developing countries' rampant lack of infrastructure development and dream of addressing the digital divide and rolling out e-government services. Furthermore, WiMAX IEEE 802.16e has demonstrated the capacity to provide connectivity and access for rural areas beyond other wireless technologies. Therefore, we simulated a testbed to determine the appropriateness of WiMAX IEEE 802.16e as an access technology for rural areas at the last-mile level.

Therefore, this study looks at various alternative options to address connectivity and access for rural areas. The study presents three scenarios, urban and peri-urban, main villages, and rural areas, and measures network efficiency based on distance from base stations, cost of deployment, and access to both LTE and WiMAX infrastructure installations.

(a) Scenario 1.

In Botswana, urban and peri-urban areas have high population densities and generally have adequate and proportionate infrastructure installations. The situation ensures that service providers experience relatively lower infrastructure deployment costs and service end-users access network services, and are less likely to experience digital divide challenges.

(b) Scenario 2.

Main villages and rural areas: These villages have populations of over 100,000 and have settlements and smaller villages about $10 \mathrm{~km}$ to $30 \mathrm{~km}$ away. Despite main villages having adequate infrastructure installations and connectivity, smaller villages close by experience a lack of broadband connectivity and access. In some of the worst situations, some villages situated along the installed fibre infrastructure not connected. The situation adversely affects social movements and businesses, as service end-users experience network service disparities and high service rates.

(c) Scenario 3.

Involves clusters of smaller villages $10 \mathrm{~km}$ to $30 \mathrm{~km}$ apart, and one village has infrastructure installations and is connected and others are not connected and are without access to broadband services.

The situations of Scenarios 2 and 3 indicate that the government and MNOs require added costs to provide services, for example for e-education, e-health, e-commerce, and other e-services, due to lack of business viability, high cost, and lack of infrastructure to support connectivity and access. Therefore, we determined whether a testbed using WiMAX 82.16e technology could address connectivity and access for cluster villages and villages on the peripheries of urban areas and main villages. 


\section{Literature Review}

Kaur et al. [11] used the Opnet 14.5 simulator to evaluate the quality of service over WiMAX IEEE802.16 standard and obtained satisfactory results. In addition, Carrillo and Seki [12] found that, despite WiMAX 802.16 being used as access technology for the Internet of Things in metro areas, it could drive agribusiness applications such as UAV operation over $45 \mathrm{~km}$ and two times $50 \mathrm{~m}$ high. The findings indicate that although the WiMAX standard is used commonly in metro areas, it is suited for rural areas. Also, Abdulrazzaq et al. [13] evaluated WiMAX 802.16 standard and found that the light (standard) VOIP service over WiMAX has no delay and throughput than voice with heavy video. This measurement indicates that using WiMAX-based networks to drive agribusiness in rural areas equally has advantages as other technologies at the last-mile level. Conclusively, Nafea and Hamza [14] found that 18 to 24 WiMAX 802.16e base stations could service a $467.34 \mathrm{~km}^{2}$ area, suggesting that the WiMAX EEE 802.16e network could address connectivity and access of clustered small villages within $10 \mathrm{~km}$ and $30 \mathrm{~km}$ apart.

The lack of relevant technology, infrastructure development, low population, and inadequate local application content in developing countries has limited internet penetration [15]. As a result, governments face the daunting task of providing connectivity and access, ensuring that end-users access e-government and other broadband services. The government should meet various obligations, such as national development programmes, millennium development goals (MDGs), and international telecommunication union treaties (ITU). However, connectivity and access challenges present opportunities for the government and other broadband stakeholders to explore technologies to address the challenges. Failure to provide citizens with connectivity and access, regardless of location, could create two types of citizens, one with access and the other not benefiting. Another challenge facing developing countries, including Botswana, is the rampant lack of support for infrastructure development, such as the lack of household power (electricity) connectivity, inadequate road networks, and equipment security.

Despite limited WiMAX installations and LTE dominance in Botswana, MNOs, ISPs, and BoFiNET have deployed the technology on some sites. According to the Research ICT Africa report, Angola, Mozambique, Nigeria, Namibia, Ghana, and other countries adopted WiMAX as an access technology in the region, and have improved their internet penetration, affordability, and mitigated connectivity challenges [16]. Although the WiMAX standard body withdrew the WiMAX $802.16 \mathrm{a} / \mathrm{b} / \mathrm{c}$, currently $802.16 \mathrm{~d} / \mathrm{e} / \mathrm{m}$ is available and provides around $50 \mathrm{~km}$ for the Line of Sight or fixed stations, and 5-15 km for non-Line of Sight or mobile stations [17]. The WiMAX IEEE $802.16 \mathrm{~d}$ could provide $70 \mathrm{Mbps}, 802.16 \mathrm{e}-15 \mathrm{Mbps}$, and $802.16 \mathrm{~m}-100 \mathrm{Mbps}$ when installed. In addition, the WiMAX standard provides three alternate topologies: fixed point to point (P2P), fixed point to multipoint (P2MP), and mobile WiMAX [17]. A mobile WiMAX topology relies on the collaborations of base stations to relay communication to subscriber stations and mobile devices that support a series of overlapping cells, which relay a signal to another base station cell and provide access [17].

Liang emphasises that only wireless access technologies can address the rural broadband connectivity challenge by deploying wireless access technologies, especially WiMAX technology [18]. Liang et al. point out that wired technologies require infrastructure installations often incompatible with developing countries' settlement patterns, which leads to higher deployment costs than for wireless technologies. The reliance on wired technologies has led developing countries to fail to deliver on several connectivity commitments from the government, such as Commonwealth Telecommunication Organization (CTO) 2015 and International Telecommunication Union (ITU) 2016. Despite the positive institutional and regulatory milestones, the RIA Botswana ICT report [19] found that Botswana's ICT readiness ranking deteriorated to the worst levels. The ICT report attributes the national broadband project's deterioration to the universal service obligations (USO), weak tariff regulations, poor quality of service (QoS) and other value-added network services, dimensions to high termination costs, and skewed market [19]. In addition, the ICT report found 
that only $9 \%$ of their study respondents used the internet and resided in urban areas, while the rest of the country experienced a lack of internet connectivity access [19].

Orange Botswana reported that the deployment of WiMAX IEEE 802.16e significantly improved the QoS and affordability of the internet connections in Francistown and Gaborone [20]. Although the WiMAX standard body initially developed technology for metro and high-density areas access, it has successfully demonstrated connectivity and access for rural areas with less infrastructure deployment [17].

\section{Material and Methods}

Shannon defines simulation as the design of a conceptual model to conduct experiments to understand a system's performance and to evaluate alternative methods. Some define simulation as the process of using inputs to drive a model, while observing its output as the model is working [21]. Therefore, simulation is seen [22] as an opportunity to understand and solve computer-based problems. According to [23], simulation consists of 11 steps, namely, system definition, model formulation, data preparation, model translation, validation, strategic planning, tactical planning, experimentation, interpretation, implementation, and documentation, which are helpful for both engineering and computer science projects. Some studies follow similar simulation procedures and processes as Seila [24], which consists of thirteen (13) steps, namely problem statement and objectives, systems analysis, analysis of input distribution, model building, design and coding of program, verification of the coded program, data analysis and design, model validation, experimental design, making production runs, statistical analysis of data, implementation, and final documentation. However, the steps align with computer science research for software development and data collection.

Therefore, this study adopted the simulation defined by Sekaran and Bougie [22]. Despite the many networking tools that vary from easy to complex, the Opnet 14.5 simulation tool remains essential for network simulation. For example, other available simulation tools include (1) QualNet, (2) NetSim, (3) SSFNet, and (4) NS2, as well as many other tools. Another factor determining the choice of simulation tools is whether they are open, commercial, proprietary, and accessible for educational and non-profit use [25]. Table 1 presents a few of the simulation tools and their comparisons using vital characteristics.

Table 1. Comparisons of some network simulation tools [22].

\begin{tabular}{|c|c|c|c|c|c|c|}
\hline Name & License Type & Language & Supported Operating & $\begin{array}{c}\text { GUI } \\
\text { Support }\end{array}$ & $\begin{array}{l}\text { Document } \\
\text { Available }\end{array}$ & $\begin{array}{l}\text { Ease of } \\
\text { Use }\end{array}$ \\
\hline QualNet & $\begin{array}{l}\text { Commercial (separate license for } \\
\text { academicians and others) }\end{array}$ & $\mathrm{C}++$ & $\begin{array}{l}\text { UNIX, Window-MAC, } \\
\text { Linux }\end{array}$ & Yes & Excellent & Moderate \\
\hline NetSim & Proprietary & C and Java & $\begin{array}{l}\text { Windows }(7, \text { Vista) and } \\
\text { Windows XP }\end{array}$ & Yes & Excellent & Easy \\
\hline SSFNet & Open-source & Java and $\mathrm{C}++$ & $\begin{array}{l}\text { Linux, Solaris, and } \\
\text { Windows NT using } \\
\text { JDK1.2 and higher }\end{array}$ & Yes & Good & Hard \\
\hline OPNET & Commercial & $\mathrm{C}$ and $\mathrm{C}++$ & $\begin{array}{l}\text { Windows XP, Vista, } 7 \& \\
\text { Windows NT } 4.0\end{array}$ & Yes & Good & Easy \\
\hline Ns2 & Open-source & $\begin{array}{l}\mathrm{C}++ \text { and } \\
\text { OTCL }\end{array}$ & $\begin{array}{c}\text { GNU / Linux, Free BS D, } \\
\text { Mac OS X, Window XP, } \\
\text { Windows Vista and } \\
\text { Win. } 7 .\end{array}$ & Limited & Excellent & Hard \\
\hline
\end{tabular}

\subsection{WiMAX IEEE 802.16e Performance Metrics Used}

\subsubsection{Traffic Sent and Receive}

Traffic sent is the amount of data transmitted by the WiMAX MAC in packets/s or bits/s. WiMAX MAC sends average bits/s to the transport layer for network transmission, 
file transfer protocol (FTP), and video conferencing for voice applications. Traffic received is the amount of data traffic transmitted successfully and received by the WiMAX MAC from the physical layer, either in packets/s or bits/s. For example, traffic received would be the average packet/data rates forwarded to the video conferencing application by the transport layer in video conferencing. The calculation to evaluate the traffic sent/received, and the study considered the WiMAX MAC packet delivery ratio (PDR) [26], which here presents the formula for packet delivery.

$$
\mathrm{PDR}=\frac{\Sigma(\text { Total Packets Received })}{\Sigma(\text { Packets Sent })}
$$

\subsubsection{Delay}

Transmission delay is the end-to-end delay of packets received, and is one of the many networks' most essential performance measurements. Delay usually specifies how long it takes for a packet/data to travel from the transmission link to the receiver node. The moment the packet leaves the transmission site or sources, it goes from the switches and is then directed to other links in the network until it reaches its destination. In simpler terms, transmission delay is the time needed to transmit all bits via a transmission medium [26].

$$
\mathrm{t}(\text { time })=\frac{(\text { Number of bits in a packet })}{(\text { total Number of transmitted packets })}
$$

\subsubsection{Jitter}

Jitter is the delay variance as the transmission sends packets through the network [26]. Jitter mostly happens when the network experiences congestion, interference, some router path changes, etc. As the transmission sends packets, they are continuous and fragmented as they arrive at the receiver, mainly because of congestion.

$$
\text { Jitter } \mathrm{J}=\mathrm{D}_{i+1}-\mathrm{D}_{i}
$$

where:

$\mathrm{D}=$ forwarding delay

$i=$ packets received

\subsubsection{Traffic Dropped}

Traffic dropped (packet lost) is the number of packets that failed to reach their destination, as a result of network interference and network congestion. To measure the traffic/packet dropped we use the packet loss rate formula [27].

$$
P L R=\frac{N^{t x}-N^{r x}}{N^{t x}} \times 100
$$

where:

$P L R=$ Packet loss rate

$N^{t x}=$ total number of transmitted packets

$N^{r x}=$ total number of received packets

\subsection{Simulation Parameters}

The simulation bed used a WiMAX base station linked/connected with nodes that formed part of the network in real situations. The nodes included a WiMAX base station, application servers, internet connection (represented by cloud), routers, and computers or CPE (customer premises equipment).

The applications relied on application configuration (Figure 1). Table 2 below summarizes various simulation scenarios; profile configuration created user profiles specified on different nodes to generate application traffic in the network, and used application configu- 
ration to configure profiles. The same configurations were applied in three scenarios; the only difference was the distance of each scenario from the WiMAX base station.

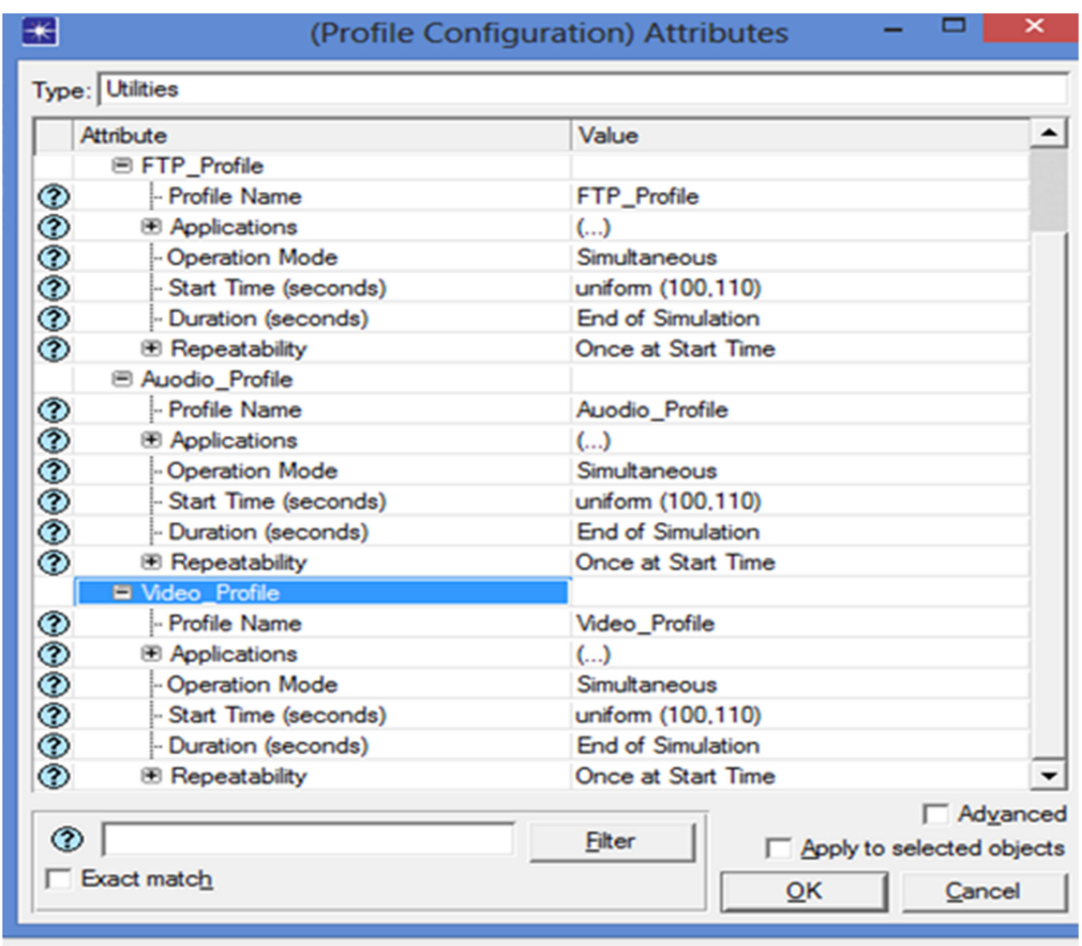

Figure 1. Applications attributes.

Table 2. Summary of simulation parameters.

\begin{tabular}{|c|c|c|}
\hline Subscriber Stations & $10 \mathrm{~km}$ from the Base Station & $20 \mathrm{~km}$ from the Base Station \\
\hline \multirow{4}{*}{$\begin{array}{l}\text { Applications Configuration } \\
\text { (Client-server) }\end{array}$} & File Transfer (FTP) & $\begin{array}{c}\text { High Load } \\
\text { ToS Best Effort (0) }\end{array}$ \\
\hline & Audio (VoIP) & $\begin{array}{l}\text { PCM Quality Speech } \\
\text { ToS Interactive Voice (6) }\end{array}$ \\
\hline & \multirow[b]{2}{*}{ Video Conferencing } & $\begin{array}{c}\text { High-resolution video } \\
\text { ToS (Type of service): Streaming Multimedia (4) }\end{array}$ \\
\hline & & $\begin{array}{l}\text { Note: } \\
\text { start-time = Constant (100) for all the applications } \\
\text { applications run over TCP /IP and UDP /IP }\end{array}$ \\
\hline \multirow{6}{*}{$\begin{array}{l}\text { WiMAX Configuration } \\
\text { parameters }\end{array}$} & Type: & Wireless OFDMA $20 \mathrm{MHz}$ \\
\hline & Node Position: & Circular \\
\hline & Antenna gain $(\mathrm{dBi})$ : & -15 \\
\hline & Transmission power: & $0.5 \mathrm{~W}$ \\
\hline & Duplexing: & TTD \\
\hline & Number of Subcarriers: & 2048 \\
\hline \multirow{3}{*}{ Point-to-point link (routers) } & routers with PPP ports: & $4 \mathrm{Mbps}$ data rate \\
\hline & Default Routing Protocol: & OSPF \\
\hline & MPLS & disabled \\
\hline
\end{tabular}

\subsection{Proposed Network Model}

The simulation network topology for this study is shown in Figure 2 and involves the following devices: 
(1) A base station (Device Name: wimax_bs_ethernet4_slip4_router): A base station sends and receives signals between a transmitting and a receiving point. For example, in mobile/cellular communication, the base station facilitates connection within a given area if the service provider is directly connected.

(2) Three servers (ppp. server model): A server node with server applications running over TCP/IP (transmission control protocol/internet protocol) and UDP/IP (user datagram protocol), and which supports one underlying SLIP connection. The data rate of the connecting link determines the operational speed to model the file transfer, audio, and video, respectively.

(3) A node (ip32_cloud- node model): An IP cloud supports up to 32 serial line interfaces and models IP traffic at a selectable data rate and routes IP packets through a cloud interface to the proper output interface, based on their destination IP addresses. Routing protocols automatically and dynamically create cloud routing tables for directing the transmitted packets.

(4) Fifteen WiMAX subscriber stations: Subscriber stations are often referred to as CPE (customer premises equipment), as they provide access at the customer side. Five subscriber stations were placed $10 \mathrm{~km}$ from the base station for the study, and another five subscriber stations were $20 \mathrm{~km}$ from the base station. The last five subscriber stations were $30 \mathrm{~km}$ away.

(5) The link (ppp_adv point-to-point link): Connects two nodes with serial interfaces (routers with PPP ports) at a selectable data rate. The transmission link connects the base station and the IP cloud with the servers for this study.

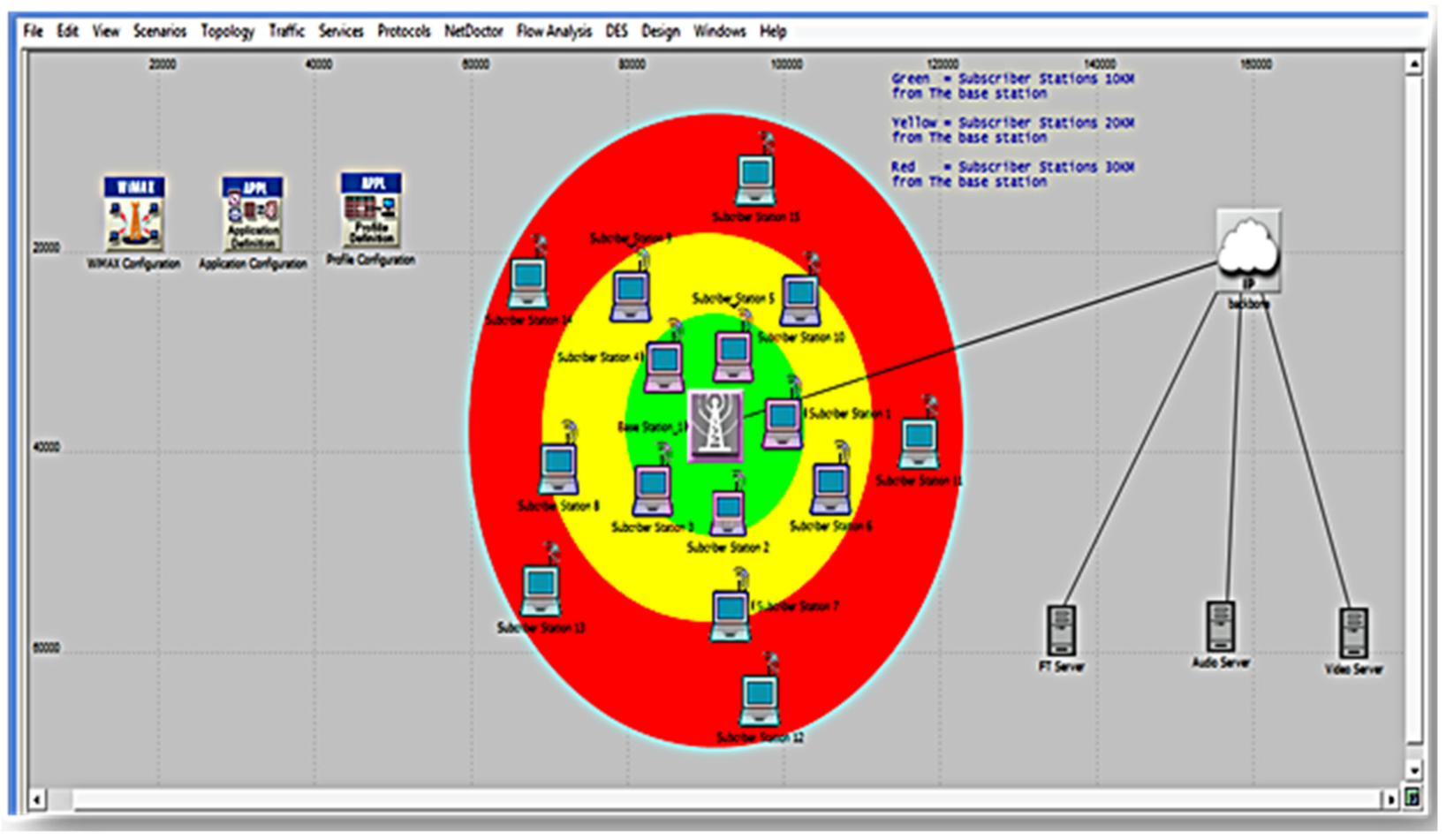

Figure 2. Simulation model.

\section{Results and Discussion}

Another observation about developing countries is the sparse settlement pattern and the heightened demand for ICT infrastructure development with the capacity to cover more areas with less deployment. Most settlements are 10 to $40 \mathrm{~km}$ away from urban areas, so whether sparse settlement patterns connectivity and access are addressed by the deployment of WiMAX 802.16e was analyzed. 
The simulation results depended on the simulation model, which evaluated the performance of WiMAX involving subscriber stations placed at various distances from the base station, at $10 \mathrm{~km}, 20 \mathrm{~km}$, and $30 \mathrm{~km}$.

Figure 3 shows Subscriber Station 1, at $10 \mathrm{~km}$; Subscriber Station 8, at $20 \mathrm{~km}$; and Subscriber Station 11, at $30 \mathrm{~km}$. Again, the same amount of $Y$-axis packets sent across the network and the simulation time ( $X$-axis) was equal for the three scenarios.

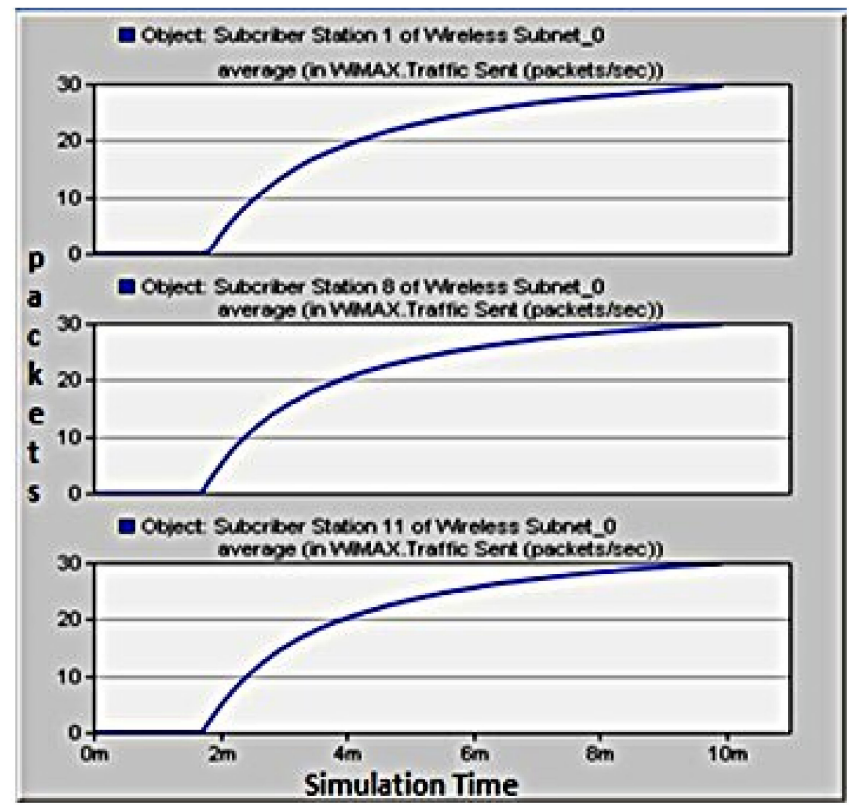

Figure 3. The initial traffic sent.

Figure 4 shows traffic received, with slight variations for the three subscriber stations. For example, packets received at $10 \mathrm{~km}$ and $20 \mathrm{~km}$ had very slight variations, while packets received at $30 \mathrm{~km}$ were significantly different. For $20 \mathrm{~km}$, the rate of packets received widened, implying that distance affects the quality of the packets received and the variations caused by a signal blockage-trees or anything else that blocked the Line of Sight. In the rural area transmission had an increased use of nodes and lower traffic to manage variations - the latter is a common feature in rural areas.

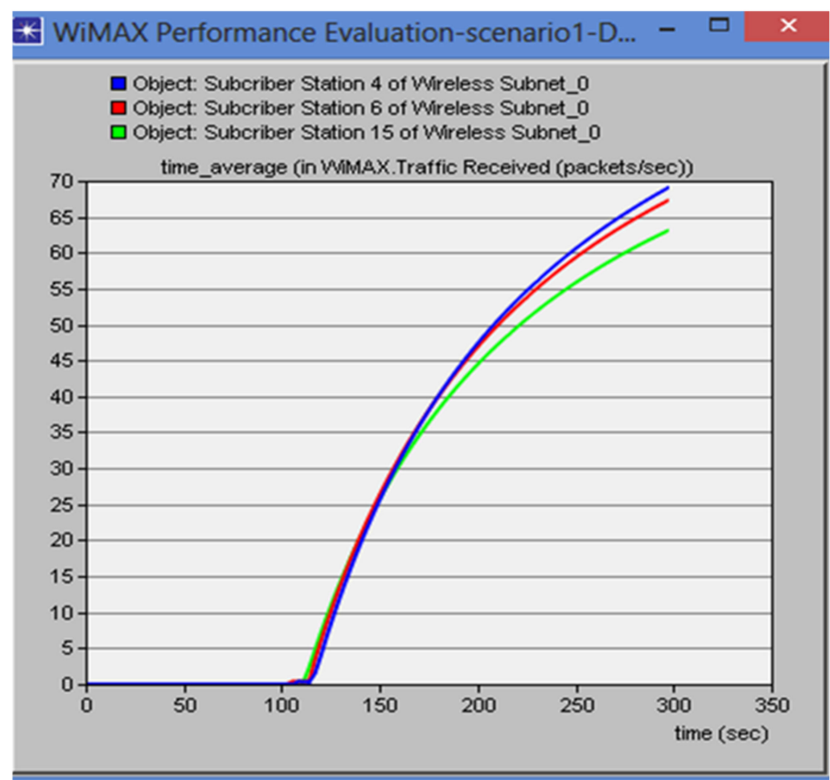

Figure 4. Traffic received after simulation. 
Figure 5 presents the average time delay of traffic from the base station to the three subscriber stations. The delay for the different subscriber stations varied: the subscriber station at $10 \mathrm{~km}$ experienced a more negligible time delay, while the subscriber station at $20 \mathrm{~km}$ experienced an average delay. In comparison, the subscriber station at $30 \mathrm{~km}$ experienced the most significant time delay.

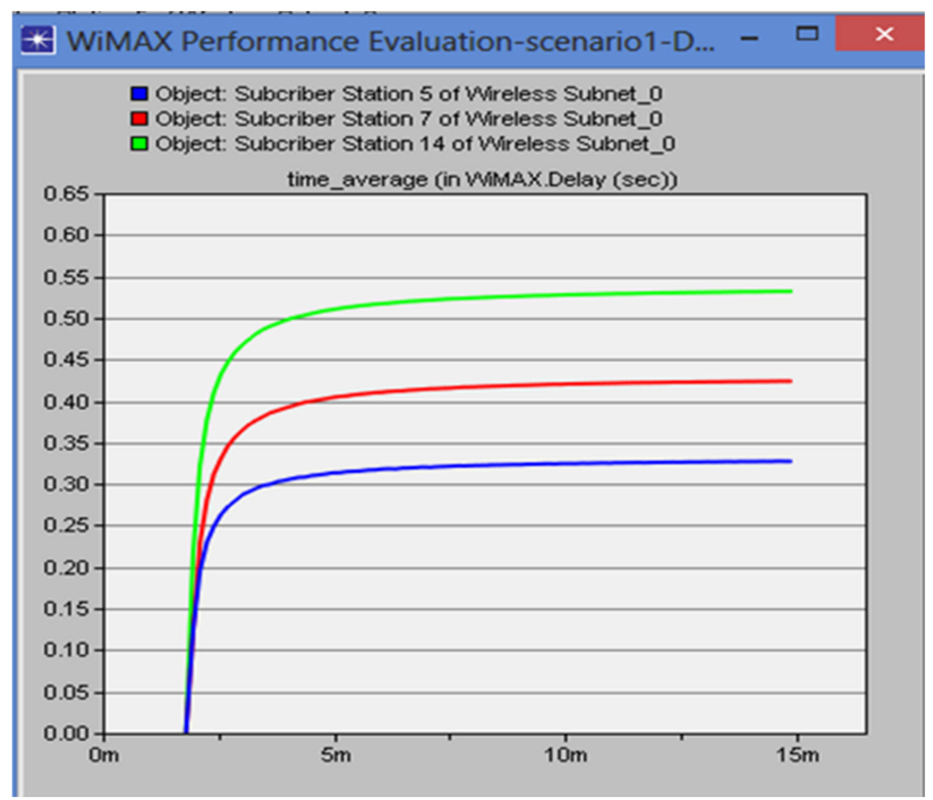

Figure 5. Traffic Delay.

In Figure 6, the average time jitter for traffic over the network upon reaching the three subscriber stations shows that the subscriber station at $30 \mathrm{~km}$ experienced jitter, even though it was low. In addition, the subscriber stations at $10 \mathrm{~km}$ and $20 \mathrm{~km}$ also experienced jitter, although less than the subscriber station at $30 \mathrm{~km}$. Inevitably, except for the jitter at the subscriber station at $30 \mathrm{~km}$, the amount of jitter dropped significantly at the other intervals.

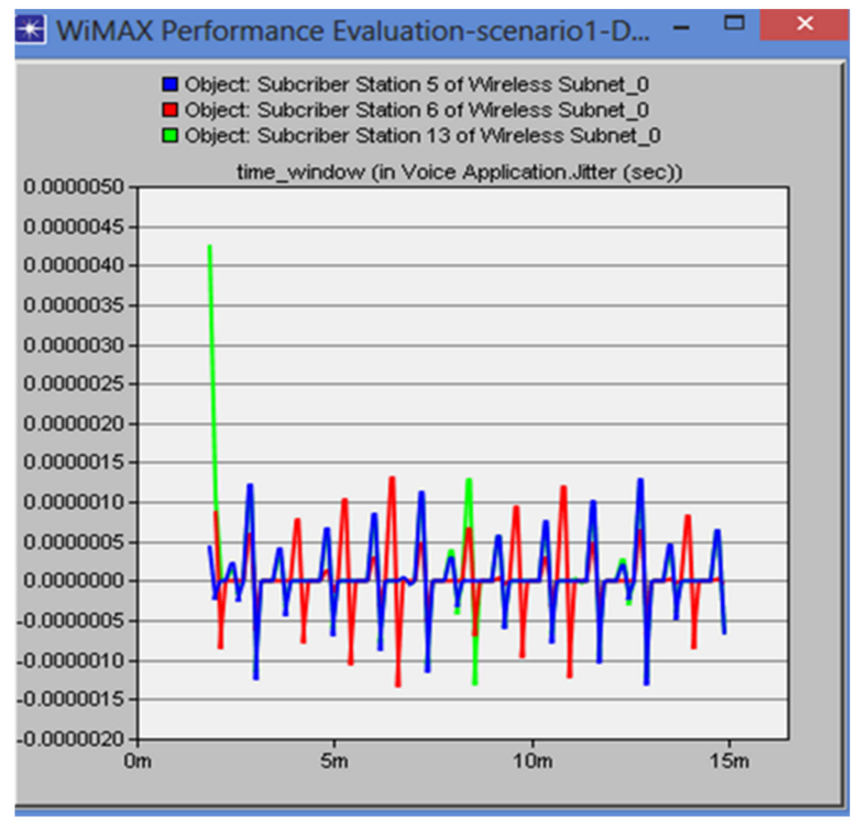

Figure 6. Jitter. 
Figure 7 presents the traffic that dropped over the network to the three different subscriber stations. The further the subscriber station from the base station, the more traffic the network would drop. However, the network consistently retained the packets, which could be attributed to the wireless MAN-FDMA (orthogonal frequency division multiple access) abilities and the TCP/UDP at the transport layer level. Using TCP/UDP ensures that the network loses or drops packets.

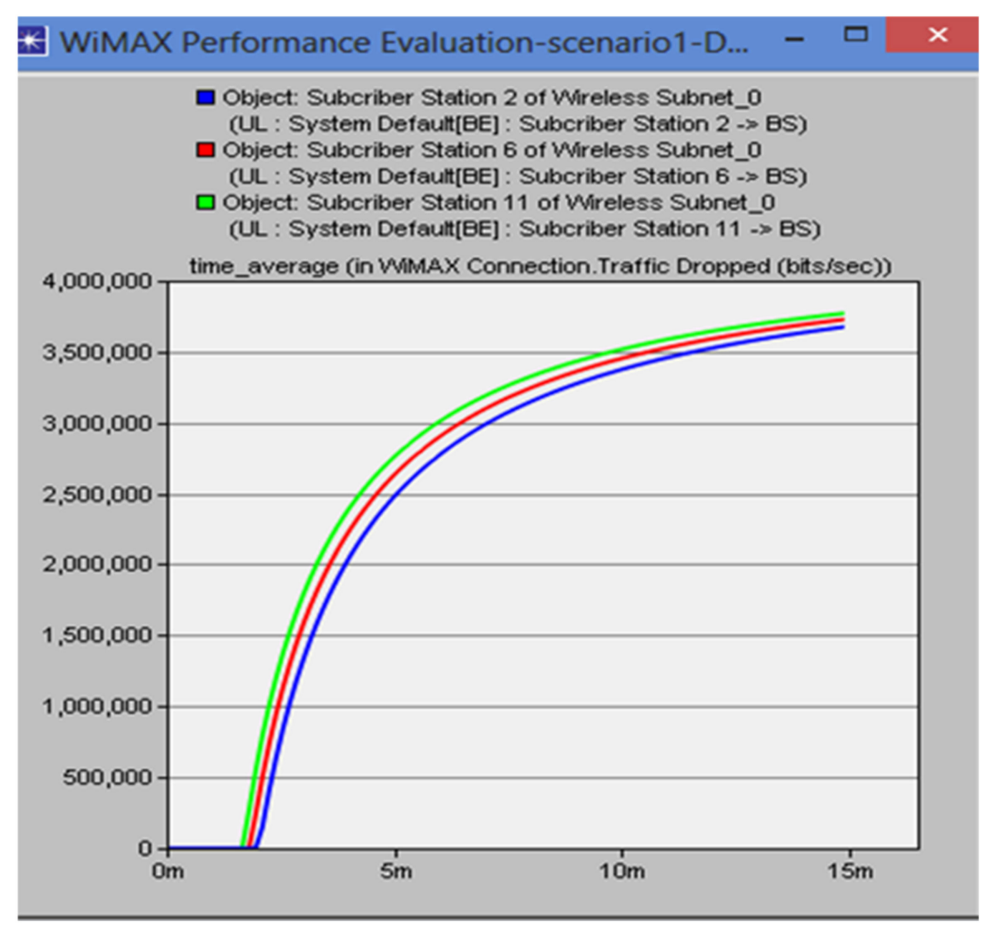

Figure 7. Traffic Dropped.

The simulation results show that metrics balance network deficit with the traffic load to optimize efficiency. For example, the continued simulation showed that the further the subscriber station, the more the jitter was reduced.

The consistency of the expected performance metric levels from the three subscriber station distance points suggests that the overall performance was better than expected. The study observed a delay over longer distances and added more nodes to boost the signal. In addition, an apparent characteristic of rural areas, namely, a low population density, means the network may optimize efficiency due to low traffic.

\section{Conclusions and Summary}

The literature review indicates that WiMAXIEEE 802.16e has a data transfer rate or speed of $70 \mathrm{Mbps}$, which is required for online transactions and standard quality of experience [28]. The simulation results indicate that settlements within 5 to $15 \mathrm{~km}$ can access Non-line of Sight, and the same infrastructure can relay signal to the next base station, with fewer infrastructure installations.

On the other hand, when using Wi-Fi as a hotspot, the current government initiative, it extends up to $90 \mathrm{~m}$ from the base station and cannot solve the last-mile connectivity and access challenges. However, adopting the WIMAX IEEE 802.16e technology to address the last-mile access challenge requires institutional and regulatory frameworks.

This study proposes a primary public network to meet universal and affordable connectivity and access. The changes could also force MNOs to diversify away from the dominant voice services, thereby achieving the national goals for an information-based economy. 


\begin{abstract}
Author Contributions: Conceptualization, B.M.E. and M.M.; methodology, B.M.E.; software, M.M.; validation, B.M.E. and M.M.; formal analysis, B.M.E.; investigation, M.M.; resources, M.M.; data curation, B.M.E.; writing—original draft preparation, M.M.; writing—review and editing, B.M.E.; visualization, B.M.E. and M.M.; supervision, B.M.E.; project administration, B.M.E.; funding acquisition, B.M.E. and M.M. All authors have read and agreed to the published version of the manuscript.
\end{abstract}

Funding: This research received no external funding.

Institutional Review Board Statement: Not applicable.

Informed Consent Statement: Not applicable.

Data Availability Statement: The data used in the simulation are contained in this article.

Acknowledgments: We would like to thank the Sol Plaatje University for assistance, as well as the Botswana Ministry of Transport and Communications (MTC), Botswana Fabre Network (BoFiNET), and Botswana Communication Regulatory Authority (BOCRA) for assisting with information on communication infrastructure about Botswana. We are also thankful to MaSIM and FNAS of the North-West University.

Conflicts of Interest: The authors of this article declare no conflict of interest.

\title{
References
}

1. $\quad$ Komane, L.S.K. How Expensive Phone Data Costs Batswana. Botswana Gazette, 6 April 2017.

2. Gilbert, P. The Most Expensive Data Prices in Africa-Connecting Africa Connecting Africa. 2019. Available online: http: / /www.connectingafrica.com/author.asp?section_id=761\&doc_id=756372 (accessed on 18 December 2019).

3. Magang, D. Internet Connectivity in Botswana: Time to Narrow Digital Divide. Weekend Post, 19 October 2020.

4. Ministry of Transport and Communications. National ICT POLICY(Maitlamo); No. 3; Government Print: Gaborone, Botswana, 2004.

5. Whalley, M.A.J.; Irvine, J. IMT standardisation and spectrum identification: Regulatory and technology implications. In Proceedings of the 2014 ITU Kaleidoscope Academic Conference: Living in a Converged World-Impossible without standards? St. Petersburg, Russia, 3-5 June 2014; pp. 63-68.

6. Foster, V.; Briceño-Garmendia, C. Africa's Infrastructure: A Time for Transformation; World Bank: Washington, DC, USA, 2010.

7. Cable.Co.Uk. Worldwide Mobile Data Pricing 2021 I 1GB Data Cost in 230 Countries. 2021. Available online: https://www.cable. co.uk/mobiles/worldwide-data-pricing/ (accessed on 21 June 2021).

8. World Bank. Infrastructure: Achievements, Challenges, and Opportunities; World Bank: Washington, DC, USA, 1994.

9. Chao, B.; Park, C. The Cost of Connectivity 2020. New America, 15 July 2020.

10. Google Maps, Goodhope, Botswana to Rakhuna. Botswana Google Maps. 2021. Available online: http:/ /lnnk.in/hzcC (accessed on 21 June 2021).

11. Kaur, A.; Sharma, A.; Singh, H. Performance comparison of wimax classesover voip. Int. J. Sci. Manag. Technol. 2016, 6, 1-51.

12. Carrillo, D.; Seki, J. Rural area deployment of internet of things connectivity: LTE and LoRaWAN case study. In Proceedings of the 2017 IEEE XXIV International Conference on Electronics, Electrical Engineering and Computing (INTERCON), Cusco, Peru, 15-18 August 2017; pp. 1-4.

13. Abdulrazzaq, A.A.; Abid, A.J.; Ali, A.H. QoS performances evaluation for mobile WIMAX networks based on OPNET. Int. J. Appl. Eng. Res. 2018, 13, 6545-6550.

14. Nafea, S.; Hamza, E.K. Path loss Optimisation in WiMAX Network using Genetic Algorithm. Iraqi J. Comput. Commun. Control Syst. Eng. 2020, 20, 1.

15. Krizanovic, V.; Zagar, D.; Grgic, K. Techno-economic analyses of wireline and wireless broadband access networks deployment in Croatian rural areas. In Proceedings of the 11th International Conference on Telecommunications, Graz, Austria; 2011; pp. 265-272.

16. LaRose, R.; Gregg, J.L.; Strover, S.; Straubhaar, J.; Carpenter, S. Closing the rural broadband gap: Promoting the adoption of the internet in rural America Telecomm. Policy 2007, 31, 59-373. [CrossRef]

17. Simba, F.; Mwinyiwiwa, B.; Mvungi, N.; Mjema, E.; Trojer, L. Broadband access technologies for rural connectivity in developing countries. Int. J. Res. Rev. Comput. Sci. 2011, 2, 2.

18. Liang, Y.-C.; Hoang, A.T.; Chen, H.-H. Cognitive radio on TV bands: A new approach to provide wireless connectivity for rural areas. Wirel. Commun. IEEE 2008, 15, 16-22. [CrossRef]

19. Esselaar, S.; Sebusang, S. What Is Happening in ICT in Botswana; Research ICT Africa: Cape Town, South Africa, 2013.

20. ITWeb. Orange Botswana Selects Alvarion for Wimax Turnkey Project ITWeb. 2009. Available online: https://www.itweb.co.za/ content/KBpdg7paXK6MLEew (accessed on 20 July 2021).

21. Bratley, P.; Fox, B.L.; Schrage, L.E. A Guide to Simulation; Springer Science \& Business Media: Berlin/Heidelberg, Germany, 2011.

22. Sekaran, U.; Bougie, R. Research Methods for Business: A Skill-Building Approach; John Wiley \& Sons: Hoboken, NJ, USA, 2016. 
23. Shannon, R.E. Introduction to the art and science of simulation in 1998 winter simulation conference. In Proceedings of the 1998 Winter Simulation Conference, Proceedings (Cat. No.98CH36274). Washington, DC, USA, 13-16 December 1998; Volume 1, pp. 7-14.

24. Seila, A.F. Introduction to simulation. In Proceedings of the Winter Simulation Conference, Coronado, CA, USA, 8-11 December 1996; pp. 7-15.

25. Kabir, M.H.; Islam, S.; Hossain, M.J.; Hossain, S.S. Detail comparison of network simulators. Int. J. Sci. Eng. Res. 2014, 5, 203-218.

26. Poretsky, S.; Perser, J.; Erramilli, S.; Khurana, S. Terminology for Benchmarking Network-Layer Traffic Control Mechanisms. IETF RFC 4689. October 2006. Available online: https://www.hjp.at/doc/rfc/rfc4689.html (accessed on 21 July 2021).

27. Lee, Y.L.; Loo, J.; Chuah, T.C. Modeling and performance evaluation of resource allocation for LTE femtocell networks. In Modeling and Simulation of Computer Networks and Systems; Elsevier: Amsterdam, The Netherlands, 2015; pp. $683-716$.

28. Choudhary, R.C.; Gupta, V. The Role of IEEE802. 16e Mobile WiMAX. Int. J. Comput. Appl. 2013, 70, 14-19. 